\title{
The relationship between fear of COVID-19 and anxiety in Honduran population
}

Miguel Landa-Blanco ${ }^{\mathrm{a} *}$, Cindy Santos-Midence ${ }^{\mathrm{b}}$, Ana Lucía Landa-Blanco ${ }^{\mathrm{b}}$, Elizabeth Andino-Rodriguez ${ }^{\mathrm{a}}$, and Antonio Cortés-Ramos ${ }^{\mathrm{c}}$

aMaster's degree of Clinical Psychology, National Autonomous University of Honduras, Tegucigalpa, Honduras; ${ }^{\mathrm{b}}$ Independent researcher, Tegucigalpa, Honduras; University of Malaga, Spain.

*Correspondence regarding this article can be sent to Miguel Landa-Blanco at miguel.landa@unah.edu.hn; ORCID: 0000-0002-7865-7593

\begin{abstract}
The purpose of this research was to determine the relationship between fear of COVID-19 and anxiety in the Honduran population. This was made through a quantitative methodology, using the Fear of COVID-19 Scale (FCV-19S) and the Generalized Anxiety Disorder-7 (GAD-7). The sample consisted of 595 Honduran respondents, with a mean age of 25.10 years. The results suggest that female participants reported significantly higher scores in fear of COVID-19 and anxiety than men. A linear regression model determined that fear of COVID-19, sex and age were significant predictors of anxiety scores. The overall model had an $r^{2}$ of 0.325, with fear of COVID-19 accounting for 29.9\% of the variance in GAD-7 scores. The resulting model has a large effect size, $f^{2}=0.48$. The results are discussed considering prior research and their psychosocial implications.
\end{abstract}

Keywords: COVID-19, pandemic, anxiety, fear of COVID-19, mental health, health psychology, coronavirus 


\section{Introduction}

\section{Origin of the COVID-19 Pandemic}

The coronavirus disease (COVID-19) is a transmittable and viral infection which is caused by severe acute respiratory syndrome coronavirus 2 (SARS-CoV-2). At the end of 2019, COVID-19 emerged in Wuhan, China as a pneumonia with unfamiliar and unknown etiology. Initially, the National Health Commission of China and the World Health Organization suggested that the first patients might have visited Hunan seafood Market in Wuhan, where live animals are sold, such as bats, frogs, snakes, birds, etc. There are different kinds of coronaviruses that circulate in a range of animals, sometimes these viruses can spread from animals to humans causing illness. By March 2020, The World Health Organization recognized SARS-Co-V-2 as a public health concern and declared it a pandemic (Shereen et al., 2020).

There are two modes of transmission of COVID-19, direct and indirect. Transmission via aerosol is a direct mode where respiratory droplets spread while talking, coughing, and sneezing of an infected patient or during surgical and dental procedures. Indirect transmission usually occurs via fomites, surfaces or objects used on an infected patient such as a stethoscope or thermometer. The indirect mode can sometimes be underestimated because it does not represent a right risk of transmission, but it always contributes to the spread of the virus (Karia et al., 2020). COVID-19 includes some typical symptoms such as fever, shortness of breath and cough and some atypical symptoms like rhinorrhea, muscle aches, headache, diarrhea, fatigue, and alteration of sense of smell or taste. But the full spectrum of symptoms is still being investigated (Pullen et al., 2020).

As of November 15, there were 53,766,728 confirmed COVID-19 cases and 1,308,975 deaths reported worldwide (World Health Organization, 2020). In Honduras, 
the first case of COVID-19 was detected on March 10, 2020. As of 14th of November of that same year the country reported 102,245 positive cases of COVID-19, that is equivalent to an incidence rate of 1,099 cases per 100,000 inhabitants. Honduras also reported a total of 2,819 fatalities due to COVID-19, which is equivalent to a mortality rate of 30 deaths per 100,000 inhabitants (Health Secretary, 2020).

\section{Fear of COVID-19 and anxiety}

Anxiety is characterized as a state of alert in which potential threats are evaluated to prepare the organism's response systems (Swift et al., 2014). Functional levels of anxiety allow the organism to cope with threating or unanticipated situations. However, persistently high levels of anxiety have detrimental effects on the subject's coping capability (Steimer, 2002).

Fear is a response to dangerous stimulus (Mertens et al., 2020). Although fear and anxiety are both basic reactions whose purpose is to preserve life, they are differentiated, while sometimes overlapping constructs. For instance, fear is detonated by specific threats, and is characterized by avoidant behaviours, present-oriented temporal focus in which the fearful response dissipates rapidly. While anxiety has a more diffused genesis with a future oriented temporal focus characterized by sustained hypervigilance (Sylvers et al., 2011).

Recent research also states that fear of COVID-19 and generalized anxiety are two distinct, although related constructs (Schweda et al., 2021). Additionally, fear of COVID-19 is related to health anxiety, perceived health risks for loved ones and social media usage (Mertens et al., 2020). It's been also found that mental health indicators such as generalized anxiety and levels of distress had increased in the initial stages of the pandemic (Schweda et al., 2021). If these feelings are persistent, they may cause 
physical functional disorders such as: palpitations, insomnia and chest tightness, and in further progressions they could lead to physical and mental diseases like depression, anxiety, endocrine disorders and hypertension (Martínez-Lorca et al., 2020). Excessive fear during the COVID-19 pandemic may also result in dysfunctional social behaviours like panic shopping and stigmatization toward positive cases. While low levels of COVID-19 related fear may result in reckless behaviour regarding biosecurity measures (Mertens et al., 2020). However, fear could also develop functional responses in which people follow safety protocols, such as wearing masks or washing hands (Schweda et al., 2021).

\section{Purpose of the study}

Considering the importance of mental health during the COVID-19 pandemic (Salari et al., 2020), the purpose of the current research was to determine the relationship between fear of COVID-19 and anxiety in the Honduran population. This is of particular relevance when considering that the Latin American region has a lacking production of scientific research regarding mental health topics (Razzouk et al., 2007).

\section{Materials and methods}

\section{Data collection techniques}

\section{Generalized Anxiety Disorder (GAD-7)}

The Generalized Anxiety Disorder (GAD-7) is a self-reported screening tool consisting of seven Likert-type items, each with four option response set $(0=$ not at all, $1=$ several days, $2=$ more than half the days, $3=$ nearly every day) (Spitzer et al., 2006). The added scores range from a minimum of 0 to a maximum of 21 , greater scores 
indicate a higher intensity of anxiety symptoms during the past two weeks.

The GAD-7 possess a an univariate structure and solid psychometric properties (Jordan et al., 2017). The GAD-7 has concurrent validity in reference to the Beck Anxiety Inventory $(r=0.69, p<0.01)$, and the anxiety subscale of the Symptom Check List-90 ( $r=0.76, p<0.01)$ (Johnson et al., 2019). The present study determined that the GAD-7 had adequate internal consistency coefficients ( $\alpha=0.90$; average interitem correlation $=0.575)$.

\section{Fear of COVID-19 Scale (FCV-19S)}

The Fear of COVID-19 Scale (FCV-19S) includes seven items with a five-point Likert-type scale response set ( $1=$ strongly disagree, $2=$ disagree, $3=$ neither agree nor disagree, $4=$ agree, $5=$ strongly agree). The added scores range from a minimum of 7 to a maximum of 35, greater scores indicate a higher fear of COVID-19. The FCV-19S has an unidimensional structure and adequate validity and reliability (Ahorsu et al., 2020). The present study determined that the FCV-19S had an internal consistency coefficient of 0.88 , as measured through Cronbach's $\alpha$ and an average interitem correlation of 0.52 .

\section{Demographic questionnaire}

The demographic questionnaire collected data regarding the respondent's sex, age, place of residence (as living or not in Honduras).

\section{Sample}

The sample consisted of 595 respondents selected through a non-probabilistic approach. The questionnaires were distributed online via social media and snow-ball sampling. The inclusion criteria were: 1) being 18 years or older, 2) to be currently living in Honduras, 3) agreeing to the informed consent. The sample included 369 
women $(62.02 \%)$ and 226 men (37.98\%); the respondent's mean age was of 25.10 years $(\mathrm{SD}=8.21 ;$ minimum age $=18 ;$ maximum age $=62)$.

\section{Ethical considerations}

An informed consent was included in the beginning of each questionnaire, it stated the purpose of the study, a confidentiality agreement, the respondent's activities, and the researcher's contact information. The consent form also included a link to the School of Psychological Science website, of the National Autonomous University of Honduras (UNAH), here, participants could access free online psychological assistance if required. Agreeing with the consent form was necessary to start the survey. The research followed all ethical considerations required by the Master's degree in Clinical Psychology of the UNAH.

\section{Data analysis}

Independently, the internal consistency coefficients of each scale were determined through Cronbach's alpha. The GAD-7 and FCV-19S item scores were added to obtain total scores, central tendency and dispersion measures were used to describe the data. A hierarchical linear regression model controlling for the respondent's sex and age was used to assess the relationship between fear of COVID-19 and GAD-7 scores. The significance of the results was determined at a 95\% confidence interval. A post-hoc analysis using $\mathrm{G}^{*}$ Power 3.1.9.7 was used to determine the effect size of the regression model and its power (Faul et al., 2009). All statistical analysis was made through JASP, version 0.14 (JASP Team, 2020) and Jamovi 1.2 (The Jamovi Project, 2020). 


\section{Results}

\section{Description of Fear of COVID-19 scores}

The average score of the FCV-19S was of 19.17 ( $S D=7.38)$. Female respondents $(M=20.05 ; S D=6.98)$ reported significantly higher scores than men $(M=17.75 ; S D=7.80)$ in fear of COVID-19, Welch's $t(435.83)=-3.63, p<0.001, d=-0.31$. Fear of COVID-19 is also significant related with the respondent's age, $r=0.11, p<0.01,95 \% C I[0.03$, $0.19]$.

\section{Description of GAD-7 scores}

The average score of the GAD-7 was of $9.06(S D=6.25)$. Female respondents $(M=9.75 ; S D=6.06)$ reported significantly higher scores than men $(M=7.93 ; S D=6.41)$ in fear of COVID-19, Welch's $t(455.12)=-3.43, p<0.001, d=-0.29$. There is no statistically significant relationship between GAD-7 scores and the respondent's age, $r=-0.06, p=0.15,95 \%$ CI $[-0.14,0.02]$.

\section{Effects of fear of COVID-19 in GAD-7 scores}

A hierarchical linear regression model was used to determine the effects of COVID-19 fear on the GAD-7 scores, while controlling for the respondent's sex and age. Model 1, included sex and age as independent variables, while Model 2 also included the scores in the Fear of COVID-19 scale. Model 1 resulted statistically significant, $F(2,592)=7.71, p<0.001$; with an unadjusted $r^{2}$ of 0.025 . However, Model 2, had an unadjusted $r^{2}$ of 0.325 , indicating a significant change from Model $1, r \Delta=$ $0.299, F \Delta(1,591)=262.17, p<0.001$. This implies that by itself, fear of COVID-19 accounted for $29.9 \%$ of the variance in GAD-7 scores. The effect size achieved in Model $2\left(f^{2}=0.48\right)$ is considered large, $f^{2}>0.35$ (Cohen, 1992). 
The independent variables included in Model 2 had no collinearity issues $\left(\mathrm{VIF}_{\mathrm{Sex}}=1.03\right.$, Tolerance $_{\mathrm{Sex}}=0.97 ; \mathrm{VIF}_{\mathrm{Age}}=1.02$, Tolerance $_{\text {Age }}=0.98 ; \mathrm{VIF}_{\mathrm{FCV}-19}=1.03$, Tolerance $\left._{\mathrm{FCV}-19}=0.97\right)$. The overall model test was statistically significant, $F(3,591)$ $=94.80, p<0.001$, and had an adjusted $r^{2}$ of 0.32 . Being female had a significantly effects on the GAD-7 scores $(\beta=-0.07) ; t=-2.05, p=0.04)$ as did age $(\beta=-0.13 ; t=-3.75$, $p<0.01)$ and fear of COVID-19 $(\beta=0.56 ; t=16.19, p<0.01)$, see Table 1.

Table 1. Regression model explaining GAD-7 scores.

\begin{tabular}{|c|c|c|c|c|c|c|c|c|c|}
\hline \multirow[b]{2}{*}{ Model } & Unstal & idardized & \multirow{2}{*}{$\begin{array}{c}\text { Standar } \\
\text { dized } \\
\beta\end{array}$} & \multirow[b]{2}{*}{$T$} & \multirow[b]{2}{*}{$p$} & \multicolumn{2}{|c|}{$95 \%$ CI for $\beta$} & \multicolumn{2}{|c|}{$\begin{array}{c}\text { Collinearity } \\
\text { Statistics }\end{array}$} \\
\hline & $\beta$ & SE & & & & Lower & Upper & Tolerance & VIF \\
\hline (Constant) & 11.21 & 0.86 & & 13.00 & $<0.01$ & 9.51 & 12.90 & & \\
\hline Sex & -1.92 & 0.53 & -0.15 & -3.65 & $<0.01$ & -2.95 & -0.89 & 0.99 & 1.01 \\
\hline 1 Age & -0.06 & 0.03 & -0.07 & -1.82 & 0.07 & -0.12 & 0.00 & 0.99 & 1.01 \\
\hline (Constant) & 2.82 & 0.89 & & 3.19 & $<0.01$ & 1.08 & 4.56 & & \\
\hline Sex & -0.91 & 0.44 & -0.07 & -2.05 & 0.04 & -1.77 & -0.04 & 0.97 & 1.03 \\
\hline Age & -0.10 & 0.03 & -0.13 & -3.75 & $<0.01$ & -0.15 & -0.05 & 0.98 & 1.02 \\
\hline 2 FCV-19 & 0.47 & 0.03 & 0.56 & 16.19 & $<0.01$ & 0.41 & 0.53 & 0.97 & 1.03 \\
\hline
\end{tabular}

Note. Dependent Variable: GAD-7. Sex: 0=Women; 1=Men. FCV=Fear of COVID-19.

A post-hoc analysis was made to determine the power achieved by the regression model, using the following criteria: $\alpha=0.05, n=595, r^{2}=0.325$ (with an equivalent effect size of $f^{2}=0.48$ ). This resulted in a an achieved power of $>0.99$, well above the 0.80 criteria commonly accepted (Faul et al., 2009). 


\section{Discussion}

The results of our study provide evidence to support the claim that fear of COVID-19 impacts general anxiety scores, even when accounting for sex and age in the model. Other studies have also determine that fear of COVID-19 has direct effects on anxiety experienced during the pandemic (Rodríguez-Hidalgo et al., 2020). Being female significantly increases the anxiety scores, while there is an inverse effect of the respondent's age over anxiety scores. Our findings suggest that women, when compared to men, have significantly higher fear of COVID-19. This result is similar to those reported within the Latin American context (Andrade et al., 2020; Rodríguez-Hidalgo et al., 2020). Given this, mental health strategies during the COVID-19 pandemic should use a gender-based approach in its design and implementation.

Anxiety is also related to longer hospitalization times and negative prognosis of diseases (Guo et al., 2019). Coping with anxiety is important when considering its effects on cardiovascular risk. In this sense, elevated levels of anxiety not only increases the likelihood of suffering a cardiovascular event, but may also restrain or promote the recovery process (Olafiranye et al., 2011). Additionally, there is moderate evidence that suggest the existence of a relationship between anxiety and obesity (Gariepy et al., 2010). This is relevant when considering that obesity is related to worse outcomes regarding COVID-19 infection (Sanchis-Gomar et al., 2020). Similarly, there is a relationship between cardiovascular disease and COVID-19 mortality (Nishiga et al., 2020). Considering this association between cardiovascular disease and obesity regarding negative COVID-19 outcomes, treating anxiety and its' causes may result in a better life quality for people exposed to the virus. As such, the use of psychoeducational materials could be useful to control the fear of COVID-19 (Ornell et al., 2020), and consequently, reduce symptoms of anxiety. 
Some authors have stated that fear of COVID-19 might be stimulated by mediatic exposure. In such cases, contradictory and confusing messages from different sources (official and unofficial), alarming media headlines and social networks might result in rumours, misinformation, stigma, anxiety, fear and panic ( $\mathrm{Ng} \& \mathrm{Kemp}, 2020)$. In this sense, a qualitative study in Honduran population found that people considered recurrent media exposure to news of the COVID-19 pandemic as a stressful activity. In response to this, selective media consumption may provide beneficial to mental health during the current pandemic (Vásquez et al., 2020).

Recent research has found that fear is a significant predictor of the preventive intentions regarding COVID-19 but fear also has detrimental effects on people's mental health. Therefore, it may result counterproductive to use fear-related strategies to promote COVID-10 preventive intentions. However, collectivist values (such as considering oneself as an interdependent part of society) instead of individual values (independence, uniqueness, and autonomy), are also significant predictors of peoples' preventive intentions. Hence, collectivist oriented propaganda, instead of individual or fear related strategies could prove effective at promoting COVID-19 preventive intentions (Huang et al., 2020).

The current study has limitations to be considered. The non-probabilistic nature of the sampling method may limit the inferential potential of the results and may not be representative of the Honduran population. The sample did not include children $(<18$ years) nor older adults ( $>65$ years), therefore, more research is yet needed for such populations. On the other hand, given the online nature of the data collection method, participants without internet access could not be included in our study. Additionally, no data was collected regarding the respondent's employment status. This would have provided a better understanding of the relationship between fear of COVID-19 and 
anxiety while comparing different vulnerable professions (for example: medics, nurses, etc.) to the general population. Another limitation is that the GAD-7 is a screening tool, which by itself, does not constitute a clinical diagnosis of anxiety.

Therefore, future research should include specific demographics (such as children, older adults, and health workers). It would also result relevant to compare anxiety and fear of COVID-19 scores between symptomatic, asymptomatic patients and negative cases, to have a better understanding of the psychological impact of COVID19. Finally, future research should study anxiety and fear of COVID-19 in hospital settings, this would allow to create and implement better psychological support strategies in the clinical environment.

\section{Funding}

No funding was received for this research.

\section{Disclosure statement}

The authors declare that there is no conflict of interest.

\section{Data availability statement}

The data that support the findings of this study are available from the corresponding author, MLB, upon reasonable request.

\section{Bibliography}

Ahorsu, D. K., Lin, C.-Y., Imani, V., Saffari, M., Griffiths, M. D., \& Pakpour, A. H. (2020). The Fear of COVID-19 Scale: Development and Initial Validation. International Journal of Mental Health and Addiction. https://doi.org/10.1007/s11469-020-00270-8

Andrade, E. F., Pereira, L. J., Oliveira, A. P. L. de, Orlando, D. R., Alves, D. A. G., Guilarducci, J. de S., \& Castelo, P. M. (2020). Perceived fear of COVID-19 
infection according to sex, age and occupational risk using the Brazilian version of the Fear of COVID-19 Scale. Death Studies, 1-10. https://doi.org/10.1080/07481187.2020.1809786

Cohen, J. (1992). A power primer. Psychological Bulletin, 112(1), 155-159. https://doi.org/10.1037/0033-2909.112.1.155

Faul, F., Erdfelder, E., Buchner, A., \& Lang, A.-G. (2009). Statistical power analyses using G*Power 3.1: Tests for correlation and regression analyses. Behavior Research Methods, 41(4), 1149-1160. https://doi.org/10.3758/BRM.41.4.1149

Gariepy, G., Nitka, D., \& Schmitz, N. (2010). The association between obesity and anxiety disorders in the population: a systematic review and meta-analysis. International Journal of Obesity, 34(3), 407-419. https://doi.org/10.1038/ijo.2009.252

Guo, W.-J., Wang, H.-Y., Deng, W., Huang, M.-J., Dong, Z.-Q., Liu, Y., Luo, S.-X., Yu, J.-Y., Huang, X., Chen, Y.-Z., Shen, C.-T., Ren, T.-R., Wang, W., Sun, X., Zeng, X.-X., Chen, L., Kuang, W.-H., Qiu, C.-J., Song, J.-P., ... Li, T. (2019). Effects of anxiety and depression and early detection and management of emotional distress on length of stay in hospital in non-psychiatric inpatients in China: a hospital-based cohort study. The Lancet, 394, S83. https://doi.org/10.1016/S0140-6736(19)32419-5

Health Secretary. (2020). Epidemiological report of the SARS-CoV-2 pandemic: march 11-november 142020.

Huang, F., Ding, H., Liu, Z., Wu, P., Zhu, M., Li, A., \& Zhu, T. (2020). How fear and collectivism influence public's preventive intention towards COVID-19 infection: a study based on big data from the social media. BMC Public Health, 20(1), 1707. https://doi.org/10.1186/s12889-020-09674-6

JASP Team. (2020). JASP Version 0.14 [computer software]. www.jasp-stats.org Johnson, S. U., Ulvenes, P. G., Øktedalen, T., \& Hoffart, A. (2019). Psychometric Properties of the General Anxiety Disorder 7-Item (GAD-7) Scale in a Heterogeneous Psychiatric Sample . In Frontiers in Psychology (10), p. 1713). https://www.frontiersin.org/article/10.3389/fpsyg.2019.01713

Jordan, P., Shedden-Mora, M. C., \& Löwe, B. (2017). Psychometric analysis of the Generalized Anxiety Disorder scale (GAD-7) in primary care using modern item response theory. PLOS ONE, 12(8), e0182162. https://doi.org/10.1371/journal.pone.0182162 
Karia, R., Gupta, I., Khandait, H., Yadav, A., \& Yadav, A. (2020). COVID-19 and its Modes of Transmission. SN Comprehensive Clinical Medicine, 2(10), 17981801. https://doi.org/10.1007/s42399-020-00498-4

Martínez-Lorca, M., Martínez-Lorca, A., Criado-Álvarez, J. J., Armesilla, M. D. C., \& Latorre, J. M. (2020). The fear of COVID-19 scale: Validation in spanish university students. Psychiatry Research, 293(June), 113350. https://doi.org/10.1016/j.psychres.2020.113350

Mertens, G., Gerritsen, L., Duijndam, S., Salemink, E., \& Engelhard, I. M. (2020). Fear of the coronavirus (COVID-19): Predictors in an online study conducted in March 2020. Journal of Anxiety Disorders, 74, 102258. https://doi.org/https://doi.org/10.1016/j.janxdis.2020.102258

Ng, K. H., \& Kemp, R. (2020). Understanding and reducing the fear of COVID-19. Journal of Zhejiang University. Science. B, 21(9), 752-754. https://doi.org/10.1631/jzus.B2000228

Nishiga, M., Wang, D. W., Han, Y., Lewis, D. B., \& Wu, J. C. (2020). COVID-19 and cardiovascular disease: from basic mechanisms to clinical perspectives. Nature Reviews Cardiology, 17(9), 543-558. https://doi.org/10.1038/s41569-020-04139

Olafiranye, O., Jean-Louis, G., Zizi, F., Nunes, J., \& Vincent, M. (2011). Anxiety and cardiovascular risk: Review of Epidemiological and Clinical Evidence. Mind \& Brain : The Journal of Psychiatry, 2(1), 32-37. https://pubmed.ncbi.nlm.nih.gov/21822473

Ornell, F., Schuch, J. B., Sordi, A. O., \& Kessler, F. H. P. (2020). Pandemic fear and COVID-19: mental health burden and strategies. In Brazilian Journal of Psychiatry (42), 232-235. https://doi.org/10.1590/1516-4446-2020-0008

Pullen, M. F., Skipper, C. P., Hullsiek, K. H., Bangdiwala, A. S., Pastick, K. A., Okafor, E. C., Lofgren, S. M., Rajasingham, R., Engen, N. W., Galdys, A., Williams, D. A., Abassi, M., \& Boulware, D. R. (2020). Symptoms of COVID-19 Outpatients in the United States. Open Forum Infectious Diseases, 7(7). https://doi.org/10.1093/ofid/ofaa271

Razzouk, D., Zorzetto, R., Dubugras, M. T., Gerolin, J., \& Mari, J. de J. (2007). Leading countries in mental health research in Latin America and the Caribbean. Revista Brasileira de Psiquiatria, 29(2), 118-122. https://doi.org/10.1590/S1516-44462006005000042 
Rodríguez-Hidalgo, A. J., Pantaleón, Y., Dios, I., \& Falla, D. (2020). Fear of COVID19, Stress, and Anxiety in University Undergraduate Students: A Predictive Model for Depression. In Frontiers in Psychology (11, p. 3041). https://www.frontiersin.org/article/10.3389/fpsyg.2020.591797

Salari, N., Hosseinian-Far, A., Jalali, R., Vaisi-Raygani, A., Rasoulpoor, S., Mohammadi, M., Rasoulpoor, S., \& Khaledi-Paveh, B. (2020). Prevalence of stress, anxiety, depression among the general population during the COVID-19 pandemic: a systematic review and meta-analysis. Globalization and Health, 16(1), 57. https://doi.org/10.1186/s12992-020-00589-w

Sanchis-Gomar, F., Lavie, C. J., Mehra, M. R., Henry, B. M., \& Lippi, G. (2020).

Obesity and Outcomes in COVID-19: When an Epidemic and Pandemic Collide. Mayo Clinic Proceedings, 95(7), 1445-1453. https://doi.org/https://doi.org/10.1016/j.mayocp.2020.05.006

Schweda, A., Weismüller, B., Bäuerle, A., Dörrie, N., Musche, V., Fink, M., Kohler, H., Teufel, M., \& Skoda, E.-M. (2021). Phenotyping mental health: Age, community size, and depression differently modulate COVID-19-related fear and generalized anxiety. Comprehensive Psychiatry, 104, 152218. https://doi.org/10.1016/j.comppsych.2020.152218

Shereen, M. A., Khan, S., Kazmi, A., Bashir, N., \& Siddique, R. (2020). COVID-19 infection: Origin, transmission, and characteristics of human coronaviruses. In Journal of Advanced Research (24), 91-98. Elsevier B.V. https://doi.org/10.1016/j.jare.2020.03.005

Spitzer, R. L., Kroenke, K., Williams, J. B. W., \& Löwe, B. (2006). A Brief Measure for Assessing Generalized Anxiety Disorder: The GAD-7. Archives of Internal Medicine, 166(10), 1092-1097. https://doi.org/10.1001/archinte.166.10.1092

Steimer, T. (2002). The biology of fear- and anxiety-related behaviors. Dialogues in Clinical Neuroscience, 4(3), 231-249. https://doi.org/10.31887/DCNS.2002.4.3/tsteimer

Swift, P., Cyhlarova, E., Goldie, I., \& O’Sullivan, C. (2014). Living with Anxiety: Understanding the role and impact of anxiety in our lives. Mental Health Foundation, 1-48. https://www.bl.uk/collection-items/living-with-anxietyunderstanding-the-role-and-\# 
Sylvers, P., Lilienfeld, S. O., \& LaPrairie, J. L. (2011). Differences between trait fear and trait anxiety: Implications for psychopathology. Clinical Psychology Review, 31(1), 122-137. https://doi.org/10.1016/j.cpr.2010.08.004

The Jamovi Project. (2020). Jamovi Version 1.2 [computer software]. www.jamovi.org Vásquez, G., Urtecho-Osorto, Ó. R., Agüero-Flores, M., Díaz-Martínez, M. J., Paguada, R. M., Varela, M. A., Landa-Blanco, M., \& Echenique, Y. (2020). Mental health, confinement, and coronavirus concerns: A qualitative study. Interamerican Journal of Psychology, 54(2), 1-16. https://doi.org/10.30849/ripijp.v54i2.1333

World Health Organization. (2020). COVID-19 Weekly Epidemiological Update-17 November 2020. https://www.who.int/publications/m/item/weeklyepidemiological-update---17-november-2020 